\title{
Hubungan Pengetahuan, Budaya, serta Dukungan Keluarga Terhadap Motivasi Pernikahan Dini
}

\author{
Maharani Retno Sulistya Masyithah, Hartati Eko Wardani*, Anindya Hapsari \\ Universitas Negeri Malang, Jl. Semarang No. 5 Malang, Jawa Timur, Indonesia \\ *Penulis korespondensi, Surel: hartati.eko.fik@um.ac.id
}

Paper received: 31-9-2021; revised: 14-9-2021; accepted: 21-9-2021

\begin{abstract}
The Ministry of Religious Affairs of Pamekasan Regency record that the highest rate of early age marriages in Pamekasan Regency in 2019 were in Waru District, reaching 254 cases of early age marriages. Ranged from age 16 to 21 years for 154 female teenagers dan 19 to 21 years for 100 male teenagers. The impact of early age marriage has on young can affect incidence the risk of LBW (Low Birth Weight), cervical cancer, anemia, and a high risk of maternal and infant mortality. The population in this study were 254 young women and men who were married at the age less than 21 years. The sampling used is simple random sampling technique as much 70 people. This research data collection used is a online questionnaire. The data analysis used is the Spearman rank test. there is no relationship between knowledge and motivation for early marriage ( $\mathrm{p}$ is 0.410 ) with OR is 0.100 , there was no found relationship between culture and motivation for early age marriage ( $\mathrm{p}$ is 0.792 ) with $\mathrm{OR}$ is 0.032 , and there was a relationship between family support and early age marriage motivation ( $\mathrm{p}$ is 0,000 ) with $\mathrm{OR}$ is 1,000 .
\end{abstract}

Keywords: knowledge; culture; family support; early age marriage motivation

\begin{abstract}
Abstrak
Kementerian Agama Kabupaten Pamekasan mencatat, pernikahan pada usia dini tertinggi di Kabupaten Pamekasan pada tahun 2019 berada di Kecamatan Waru, Mencapai angka 254 pernikahan usia dini. usia menikah 16-21 tahun pada remaja wanita 154 orang, usia 19-21 pada remaja laki-laki 100 orang. Dampak dari Pernikahan di usia dini dapat mempengaruhi terjadinya risiko BBLR, Kanker servik, anemia, serta berisiko tinggi terjadi angka kematian ibu dan bayi. Penelitian ini bertujuan untuk mengetahui korelasi antara variabel pengetahuan, budaya dan dukungan keluarga dengan motivasi pernikahan dini di Kabupaten Pamekasan. Dalam penelitian menggunakan metode deskripsi korelasi dengan pendekatan cross sectional. Kriteria populasi meliputi remaja perempuan dan remaja lakilaki yang telah menikah pada usia kurang dari 21 tahun sebanyak 254 orang. Sampel yang digunakan adalah teknik simple random sampling sebanyak 70 orang. Pengumpulan data penelitian ini menggunakan kuesioner online. Analisis data menggunakan uji Spearman Rank. Tidak ada hubungan antara pengetahuan dan motivasi pernikahan dini ( $\mathrm{p}$ sama dengan 0,410 ) dengan OR sama dengan $-0,100$, yang berarti tidak ada hubungan antara budaya dan motivasi pernikahan dini ( $p$ sama dengan 0,792 ) dengan OR sama dengan 0,032 , ada hubungan dukungan keluarga dan motivasi pernikahan dini ( $\mathrm{p}$ sama dengan 0,000 ) dengan OR sama dengan 1,000 .
\end{abstract}

Kata kunci: pengetahuan; budaya; dukungan keluarga; motivasi pernikahan dini

\section{Pendahuluan}

Pernikahan merupakan syariat Islam dan perintah agama. Tujuan pernikahan adalah jalan satu satunya untuk mengesahkan seks dalam agama islam (Atabik \& Mudhiiah, 2014). Untuk dapat menikah secara sah dalam agama dan diakui oleh negara, terdapat aturan dan 
hukum yang berlaku. Menurut Badan Kependudukan dan Keluarga Berencana Nasional, pernikahan ideal adalah pernikahan pada usia 25 tahun untuk pria dan 20 tahun untuk wanita (BKKBN, 2017). Pernikahan yang dilakukan sebelum usia 18 tahun disebut pernikahan dini. Menurut United Nations Children's perkawinan usia dini adalah seseorang yang melangsungkan ikatan perkawinan pada saat usia kurang dari 18 tahun, yang dilaksanakan secara resmi atau tidak resmi (UNICEF, 2020).

Berdasarkan data epidemiologi, pernikahan dini terjadi di Negara Asia Tenggara dan Afrika. Jumlah anak berusia dibawah 18 tahun di Asia Tenggara yang telah menikah adalah sekitar 10 juta anak. Melainkan di Afrika, sebanyak 42\% anak telah melakukan pernikahan di bawah umur 18 tahun. (UNICEF, 2001).

Berdasarkan data dari Badan Pusat Statistik, jumlah pernikahan pada anak di Indonesia terbilang sangat besar. Dengan adanya data Survei Demografi dan Kesehatan Indonesia, sebanyak $17 \%$ perempuan pada usia 20 tahun telah menikah pada usia kurang dari 18 tahun. Perkawinan pada anak perempuan yang berusia kurang dari 18 tahun di Indonesia mencapai 340.000 pernikahan. Sedangkan menurut data pada Survei Sosial Ekonomi Nasional pada tahun 2012 , sebanyak $25 \%$ anak perempuan pada usia 24 tahun telah melakukan perkawinan pada usia kurang dari 18 tahun. Perkawinan anak perempuan yang berusia $<18$ tahun terdapat di daerah pedesaan. Pada tahun 2008 sampai tahun 2010 terjadi tren penurunan angka prevalensi pernikahan dini. Prevalensi pernikahan dini mengalami kenaikan di tahun 2011, kemudian pada tahun 2012 mengalami stagnasi pernikahan usia anak (UN, 2020). Berdasarkan data Badan Pusat Statistik Provinsi Jawa Timur, pernikahan dibawah umur sebanyak 762,91 jiwa. Madura memiliki angka prevalensi yang cukup tinggi. Pada tahun 2016. Jumlah pernikahan dini di kabupaten Pamekasan mencapai 29,57\% (Badan Pusat Statistik Jawa Timur, 2017).

Wanita yang mengalami kehamilan pada usia muda kurang terpenuhi gizi bagi dirinya, sehingga berisiko mengakibatkan berat badan lahir rendah pada bayi (BBLR), kematian bayi menjadi resiko besar akibat BBLR. Kehamilan di usia muda berisiko ibu akan mengalami anemia sehingga dapat meningkatkan depresi pada saat kehamilan. Menurut epidemiologi kehamilan di usia muda berisiko tinggi mengalami kanker serviks (Ali, 2015). Dampak lain akibat pernikahan diusia dini adalah psikologis. Dampak pernikahan dini memiliki risiko yang tinggi untuk kesehatan mental dan psikologis wanita. Masalah kesehatan mental yang terjadi jika wanita mengalami pemaksaan seksual dalam pernikahan. Selain itu dengan melahirkan anak pada usia <20 tahun dapat menyebabkan gejala depresi, kecemasan, dan somatisasi lebih besar daripada wanita yang melahirkan anak di usia lebih dari 20 tahun (Sezgin \& Punamäki, 2019).

Adanya faktor yang dapat mempengaruhi keputusan menikah dini adalah pengetahuan (Ghoni, 2012). Penelitian lain oleh Handayani (2014) terdapat hubungan antara faktor pengetahuan dan pernikahan dini. Pengetahuan memiliki hubungan sebab akibat dengan remaja usia dini, dimana pengetahuan yang rendah dapat memotivasi keinginan remaja untuk menikah (Handayani, 2014). Penelitian terdahulu Septialti (2016) pengetahuan sangat mempengaruhi remaja untuk mengambil keputusan kapan akan menikah, remaja dengan pengetahuan kesehatan reproduksi yang baik cenderung menikah pada usia yang matang karena mengetahui risiko terhadap pernikahan yang akan lakukan (Septialti, Delita \& mawarni, 2016). 
Faktor budaya mempengaruhi keputusan menikah dini adalah budaya. Budaya adalah suatu keyakinan yang dimiliki oleh individu atau sekelompok orang yang diwariskan secara turun-temurun oleh nenek moyang dari generasi ke generasi. Kebudayaan di setiap daerah bermacam-macam. Perbedaan budaya di setiap daerah dapat dilihat dari segi Bahasa, tarian, adat istiadat, agama, kepercayaan, bangunan, pakaian adat, dan karya seni (Harni \& Nicky, 2016). Menurut Halawani (2017) terdapat hubungan antara budaya dan pernikahan dini, kebudayaan suatu daerah mempengaruhi anak perempuan untuk menikah pada usia muda, remaja perempuan yang telah memasuki 20 tahun namun belum memiliki pasangan atau belum menikah akan menjadi pembicaraan tetangga dikatakan sebagai perawan tua. Sehingga menjadi aib bagi keluarga (Halawani, 2017).

Dukungan keluarga mempengaruhi keputusan menikah dini. Terdapat hubungan antara faktor dukungan keluarga dengan pernikahan dini, dukungan yang diberikan keluarga kepada anak sangat berpengaruh besar, masa depan anak ditentukan oleh keluarga termasuk dalam pernikahan. Dan salahnya pergaulan anak yang disebabkan oleh keluarga yang tidak harmonis, sehingga menyebabkan orang tua cemas dan harus menikahkan anak dalam penelitian Sandy (2018) (Sandy, 2018).

Kabupaten Pamekasan memiliki angka prevalensi yang cukup tinggi terhadap pernikahan dini. Menurut data Kementerian Agama Kabupaten Pamekasan, dengan melihat cakupan data pernikahan pada bulan Januari hingga Desember 2019, jumlah laki-laki yang menikah di usia $<19$ tahun sebanyak 79 orang dan laki-laki yang menikah pada usia $<21$ tahun sebanyak 1472 orang. Sedangkan, perkawinan anak perempuan di usia $<16$ tahun sebanyak 69 orang, sedangkan perempuan yang berusia 16-21 tahun sebanyak 3726 orang. Jumlah keseluruhan pernikahan dini di Kabupaten Pamekasan pada tahun 2019 sebanyak 3725 jiwa.

Pernikahan dini tertinggi di kabupaten Pamekasan Menurut data Kementerian Agama Kabupaten Pamekasan, berada di Kecamatan Waru. Data dari bulan Januari hingga bulan Desember 2019 menunjukkan jumlah pernikahan dini pada laki- laki 19 tahun berjumlah sebanyak 20, sedangkan yang berusia $19-21$ berjumlah 80 orang. Jumlah pernikahan dini pada perempuan di Kecamatan Waru yang berusia dibawah 16 tahun berjumlah sebanyak 24, sedangkan yang berusia 16-21 tahun berjumlah sebanyak 130. Dapat disimpulkan jumlah data pernikahan dini laki-laki dan perempuan pada tahun 2019 di Kecamatan Waru Kabupaten Pamekasan sebanyak 254 orang.

Dengan ini peneliti memiliki ketertarikan untuk melakukan sebuah penelitian tentang hubungan pengetahuan, budaya serta dukungan keluarga terhadap motivasi pernikahan dini di Kabupaten Pamekasan Madura.

\section{Metode}

Penelitian ini adalah penelitian kuantitatif korelasional yang menggunakan pendekatan cross sectional. Adapun populasi yang ditentukan ialah laki-laki dan perempuan di Kecamatan Waru Kabupaten Pamekasan yang telah melakukan pernikahan pada usia 14-21 tahun sebanyak 254. Sampel didapatkan sebanyak 70 menggunakan teknik simple random sampling. Pengumpulan data yang diambil menggunakan instrumen penelitian kuesioner. Data yang dianalisis menggunakan uji Spearman Rank. 


\section{Hasil dan Pembahasan}

\subsection{Karakteristik Responden Berdasarkan Usia}

Tabel 1. Karakteristik Responden Berdasarkan Usia

\begin{tabular}{lcc}
\hline \multicolumn{1}{c}{ Umur } & Frekuensi & Persentase (\%) \\
\hline 14-17 tahun & 32 & 45,8 \\
18-21 tahun & 38 & 54,2 \\
Jumlah & 70 & 100 \\
\hline
\end{tabular}

Data responden dengan karakteristik berdasarkan kelompok usia 14-17 tahun sebanyak 32 (45,8\%), usia 18-21 tahun sebanyak 38 (54,2\%).

\subsection{Karakteristik Responden Berdasarkan Jenis Kelamin}

Tabel 2. Karakteristik Responden Berdasarkan Jenis Kelamin

\begin{tabular}{lcc}
\hline Jenis Kelamin & Frekuensi & Persentase (\%) \\
\hline Perempuan & 54 & 77,1 \\
Laki-laki & 16 & 22,8 \\
Jumlah & 70 & 100 \\
\hline
\end{tabular}

Berdasarkan tabel di atas menunjukkan bahwa karakteristik responden berdasarkan jenis kelamin, perempuan 54 orang $(77,1 \%)$ dan laki-laki 16 orang $(22,8 \%)$.

\subsection{Karakteristik Responden Berdasarkan Pendidikan}

Tabel 3. Karakteristik Responden Berdasarkan Pendidikan

\begin{tabular}{lcc}
\hline Pendidikan & Frekuensi & Persentase (\%) \\
\hline SD & 15 & 21,4 \\
SMP & 26 & 37,1 \\
SMA/SMK & 24 & 34,2 \\
S1 & 5 & 7,1 \\
Jumlah & 70 & 100 \\
\hline
\end{tabular}

Didapatkan hasil karakteristik dari responden berdasarkan tingkat pendidikan. SD 15 orang (21,4\%), SMP 26 orang (37,1\%), SMA/SMK 24 orang (34,2\%), Dan S1 5 orang (7,1\%). 


\subsection{Hasil Analisis Bivariat Hubungan Antara Pengetahuan dan Motivasi Menikah Dini}

Tabel 4. Hasil Analisis Bivariat Hubungan Antara Pengetahuan dan Motivasi Menikah Dini

\begin{tabular}{|c|c|c|c|c|c|}
\hline \multirow[t]{2}{*}{ Pengetahuan } & \multicolumn{2}{|c|}{ Motivasi Pernikahan Dini } & \multirow[t]{2}{*}{ Total } & \multirow[t]{2}{*}{ P-Value } & \multirow[t]{2}{*}{ Koefisien Korelasi } \\
\hline & Tidak & Ya & & & \\
\hline \multirow[t]{2}{*}{ Kurang } & 7 & 10 & 17 & 0,410 & $-0,100$ \\
\hline & $41 \%$ & $59 \%$ & $100,0 \%$ & & \\
\hline \multirow[t]{2}{*}{ Baik } & 28 & 25 & 53 & & \\
\hline & $53 \%$ & $47 \%$ & $100,0 \%$ & & \\
\hline \multirow[t]{2}{*}{ Total } & 35 & 35 & 70 & & \\
\hline & $50 \%$ & $50 \%$ & $100,0 \%$ & & \\
\hline
\end{tabular}

Berdasarkan uji korelasi didapatkan nilai signifikansi $p=0,410$ sehingga lebih besar dari 0,05. Ha ditolak dan Ho diterima, maka hasil uji Spearman Rank tidak ada hubungan antara pengetahuan dan motivasi pernikahan dini. Nilai koefisien korelasi yaitu -0,100 berarti kekuatan korelasi lemah. Didapatkan nilai minus karena berlawanan arah antara pengetahuan dan motivasi.

Sesuai dengan penelitian Waroh (2020) dengan judul "Hubungan antara Pengetahuan Remaja Tentang Kesehatan Reproduksi dengan Pernikahan Dini di Desa Panggung, Kecamatan Sampang, Kabupaten Sampang" dengan hasil $(\mathrm{P}=0.006>0,05)$ artinya tidak ada hubungan pengetahuan dan pernikahan dini. Didukung dengan penelitian Setywani (2019) "Hubungan Pengetahuan Remaja Dan Resiko Pernikahan Dini Dengan Keinginan Melakukan Pernikahan Dini di SMK Kanisius Ungaran di Kabupaten Semarang" dengan hasil $P=0,392$ kurang dari 0,05 ) tidak terdapat hubungan pengetahuan dan motivasi pernikahan dini.

Adapun perbedaan yang didapatkan oleh peneliti antara lain metode pengambilan sampel, jumlah sampel, serta analisa data yang digunakan. Hal ini memungkinkan untuk menciptakan hasil yang tidak signifikan pada hasil penelitian yang dilakukan oleh peneliti. Hal yang mempengaruhi tidak ada hubungan antara pengetahuan dan motivasi pernikahan dini yaitu pertanyaan pada kuesioner pengetahuan kurang, sehingga tidak sebanding dengan pertanyaan pada kuesioner motivasi pernikahan dini. Selain itu, karena ada beberapa responden yang telah lanjut usia, kemungkinan kurang paham dengan pernikahan dini sehingga asal mengisi kuesioner. Dan juga, hasil data kuesioner responden pada pengetahuan dan motivasi pernikahan dini tidak konsisten.

\subsection{Hasil Analisis Bivariat Hubungan Antara Budaya dan Motivasi Menikah Dini}

Tabel 5. Hasil Analisis Bivariat Hubungan Antara Budaya dan Motivasi Menikah Dini

\begin{tabular}{|c|c|c|c|c|c|}
\hline \multirow[t]{2}{*}{ Budaya } & \multicolumn{2}{|c|}{ Motivasi Pernikahan Dini } & \multirow[t]{2}{*}{ Total } & \multirow[t]{2}{*}{ P-Value } & \multirow[t]{2}{*}{ Koefisien Korelasi } \\
\hline & Tidak & Ya & & & \\
\hline \multirow[t]{2}{*}{ Kurang } & 10 & 9 & 19 & 0,792 & 0,032 \\
\hline & $53 \%$ & $47 \%$ & $100,0 \%$ & & \\
\hline \multirow[t]{2}{*}{ Baik } & 25 & 26 & 53 & & \\
\hline & $49 \%$ & $51 \%$ & $100,0 \%$ & & \\
\hline \multirow[t]{2}{*}{ Total } & 35 & 35 & 70 & & \\
\hline & $50 \%$ & $50 \%$ & $100,0 \%$ & & \\
\hline
\end{tabular}


Berdasarkan hasil tabulasi silang menunjukkan hasil $p$ 0,792 >0,005. Tidak terdapat hubungan signifikan budaya dan motivasi pernikahan dini. Koefisien korelasi yaitu 0,032 berarti kekuatan korelasi lemah.

Penelitian yang dilakukan oleh Surya (2020) ada kesamaan dengan penelitian yang dilakukan oleh peneliti yang berjudul "Hubungan Sumber informasi, Budaya dan Keluarga dengan Pernikahan Dini pada Wanita PUS (Pasangan Usia Subur) di Desa Tembung Kecamatan Percut Sei Tuan Kabupaten Deli Serdang" hasil uji Spearman Rank 0,614 yang berarti tidak ada hubungan budaya dan pernikahan dini.

Penelitian lain yang juga sejalan ialah penelitian Mahendra (2019), disebutkan tidak ada hubungan yang bermakna kearena nilai $p=1,000>0,05$, maka tidak ditemukan hubungan antara budaya dan pernikahan dini.

Adanya perbedaan dalam penelitian ini dengan penelitian lain. Perbedaan tersebut antara lain metode pengambilan sampel, jumlah sampel, serta analisis data yang digunakan. Adapun hal lain yang mempengaruhi korelasi pada setiap variabel yaitu jumlah pertanyaan dalam kuesioner budaya kurang, dan juga hasil data kuesioner pada budaya dan motivasi pernikahan dini tidak homogen.

\subsection{Hasil Analisis Bivariat Hubungan Antara Dukungan Keluarga dan Motivasi Menikah Dini}

Tabel 6. Hasil Analisis Bivariat Hubungan Antara Dukungan Keluarga dan Motivasi Menikah Dini

\begin{tabular}{lccccc}
\hline Dukungan & \multicolumn{2}{c}{ Motivasi Pernikahan Dini } & Total & P-Value & Koefisien Korelasi \\
\cline { 2 - 3 } Keluarga & Tidak & Ya & & & 1,000 \\
Kurang & 35 & 0 & 35 & 0,000 & \\
& $100 \%$ & $0 \%$ & $100,0 \%$ & & \\
Baik & 0 & 35 & 35 & \\
& $0 \%$ & $100 \%$ & $100,0 \%$ & \\
Total & 35 & 35 & 70 & \\
& $50 \%$ & $50 \%$ & $100,0 \%$ & \\
\hline
\end{tabular}

\section{Simpulan}

Tidak terdapat hubungan antara budaya dan motivasi pernikahan dini di Kecamatan Waru Kabupaten Pamekasan. Nilai signifikansi $p=0,410$ sehingga lebih besar dari 0,05. Tidak ada hubungan antara budaya dengan motivasi pernikahan dini di Kecamatan Waru Kabupaten Pamekasan. Nilai $p$ value sebesar 0,792 >0,05. Terdapat hubungan antara dukungan keluarga dengan motivasi pernikahan dini di Kecamatan Waru Kabupaten Pamekasan. $p$ value $=0,00$ $>0,05$.

\section{Daftar Rujukan}

Ali, S. (2015). Perkawinan Usia Muda Di Indonesia Dalam Perspektif Negara Dan Agama Serta Permasalahannya (The Teen Marriage In Indonesia On The Country Perspective And Religion As Well As The Problem ). Jurnal Legislasi Indonesia, 12(2), 1-28.

Atabik, A., \& Mudhiiah, K. (2014). Pernikahan dan Hikmahnya Perspektif Hukum Islam. Yudisia, 5(2), 293-294.

Badan Pusat Statistik Jawa Timur. (2017). Persentase Perempuan Jawa Timur Usia 10 Tahun Ke Atas yang Kawin di Bawah Umur (Kurang dari 17 Tahun) menurut Kabupaten/Kota, 2009-2016. 
https://jatim.bps.go.id/statictable/2017/06/09/465/persentase-perempuan-jawa-timur-usia-10tahun-ke-atas-yang-kawin-di-bawah-umur-kurang-dari-17-tahun-menurut-kabupaten-kota-20092016-.html

BKKBN. (2017). Usia Pernikahan Ideal 21-25 Tahun. https://www.bkkbn.go.id/detailpost/bkkbn-usiapernikahan-ideal-21-25-tahun

Ghoni, H. A. A. (2012). Pengaruh motivasi dan pengetahuan wajib pajak terhadap kepatuhan wajib pajak daerah. Jurnal Akuntansi AKUNESA, 1(1).

Handayani, E. Y. (2014). Faktor-Faktor Yang Berhubungan Dengan Pernikahan Usia Dini Pada Remaja Putri Di Kecamatan Tambusai Utara Kabupaten Rokan Hulu. Jurnal Martenity and Neonatal, 1(5), 200-206.

Kusniyati, H., \& Sitanggang, N. S. P. (2016). Aplikasi Edukasi Budaya Toba Samosir Berbasis Android. Jurnal teknik informatika, 9(1).

Pohan, N. H. (2017). Faktor-Faktor yang Berhubungan Dengan Pernikahan Usia Dini terhadap Remaja Putri. Jurnal Endurance: Kajian Ilmiah Problema Kesehatan, 2(3), 424-435.

Sandy, N. (2018). Hubungan Dukungan Keluarga Dan Budaya Dengan Pernikahan Usia Dini Pada Perempuan Di Kampung Cibeo Kelurahan Kemanisan Kota Serang Tahun 2018. Jurnal Ilmiah Kesehatan Delima, 1(1), 45-53. https://doi.org/10.1017/CB09781107415324.004

Septialti, D., Mawarni, A., Nugroho, D., \& Dharmawan, Y. (2017). Hubungan Pengetahuan Responden dan Faktor Demografi dengan Pernikahan Usia Dini di Kecamatan Banyumanik Tahun 2016. Jurnal Kesehatan Masyarakat (Undip), 5(4), 198-206.

Sezgin, A. U., \& Punamäki, R. L. (2020). Impacts of early marriage and adolescent pregnancy on mental and somatic health: the role of partner violence. Archives of women's mental health, 23(2), 155.

UN. (2020). Pencegahan Perkawinan Anak.

UNICEF. (2001). EARLY MARRIAGE CHILD SPOUSES. www.unicef-icdc.org

UNICEF. (2020). Child marriage / UNICEF. https://www.unicef.org/protection/child-marriage 